\title{
Heart Rhythm
}

National Cancer Institute

\section{Source}

National Cancer Institute. Heart Rhythm. NCI Thesaurus. Code C87081.

The recurrent, measured movements (rhythm) of a beating heart. 